\title{
Comparative Analysis of Torque and Acceleration of Pre- and Post- Transmission Parallel Hybrid Drivetrains
}

\author{
Saiful A. Zulkifli ${ }^{1,3, a}$, Nordin Saad ${ }^{2}$ and A. Rashid A. Aziz ${ }^{2,3}$ \\ ${ }^{1}$ Electrical and Electronics Engineering Department \\ ${ }^{2}$ Mechanical Engineering Department \\ ${ }^{3}$ Centre for Automotive Research and Electric Mobility (CAREM) \\ Universiti Teknologi PETRONAS, 32610 Seri Iskandar, Perak, Malaysia
}

\begin{abstract}
Parallel hybrid electric vehicles (HEV) can be classified according to the location of the electric motor with respect to the transmission unit for the internal combustion engine (ICE): they can be pre-transmission or posttransmission parallel hybrid. A split-axle parallel HEV - in which the ICE and electric motor provide propulsion power to different axles - is a sub-type of the post-transmission hybrid, since addition of torque and power from the two power sources occurs after the vehicle's transmission. The term 'through-the-road' (TTR) hybrid is also used for the split-parallel HEV, since power coupling between the ICE and electric motor is not through some mechanical device but through the vehicle itself, its wheels and the road on which it moves. The present work presents torquespeed relationship of the split-parallel hybrid and analyses simulation results of torque profiles and acceleration performance of pre-transmission and post-transmission hybrid configurations, using three different sizes of electric motor. Different operating regions of the pre-trans and post-trans motors are observed, leading to different speed and torque profiles. Although ICE average efficiency in the post-trans hybrid is slightly lower than in the pre-trans hybrid, the post-trans hybrid vehicle has better fuel economy and acceleration performance than the pre-trans hybrid vehicle.
\end{abstract}

\section{Introduction}

A parallel hybrid electric vehicle typically has the electric motor-generator on board the chassis, as in most production hybrids of today, but in one variant of the parallel hybrid, the electric motor is part of the wheel itself, called a hub motor, or in-wheel motor (IWM). In this configuration (Figure 1), the ICE operates on one drive-shaft (e.g., front) while the in-wheel motors are fitted into the other pair of wheels (e.g., rear), resulting in a split-axle parallel architecture $[1,2]$.

There is no specific device coupling the two propulsion sources; instead, the power sources are coupled through the road, giving rise to the term TTR hybrid. This configuration enables an existing ICE-driven vehicle to be converted into a hybrid electric vehicle with minimal modification - by replacing the otherwise nondriven wheels with in-wheel motors (IWM) and powering them with a battery bank located in the vehicle's trunk. Along with motor controllers and an energy management system controller (EMS) that intelligently manages the vehicle's energy and power flow, they form a TTR-IWM hybrid vehicle system.

Figure 2 shows three different configurations of the parallel hybrid drive-train: a TTR-IWM split-axle parallel hybrid, a single-axle post-transmission parallel hybrid, and a single-axle pre-transmission parallel hybrid.
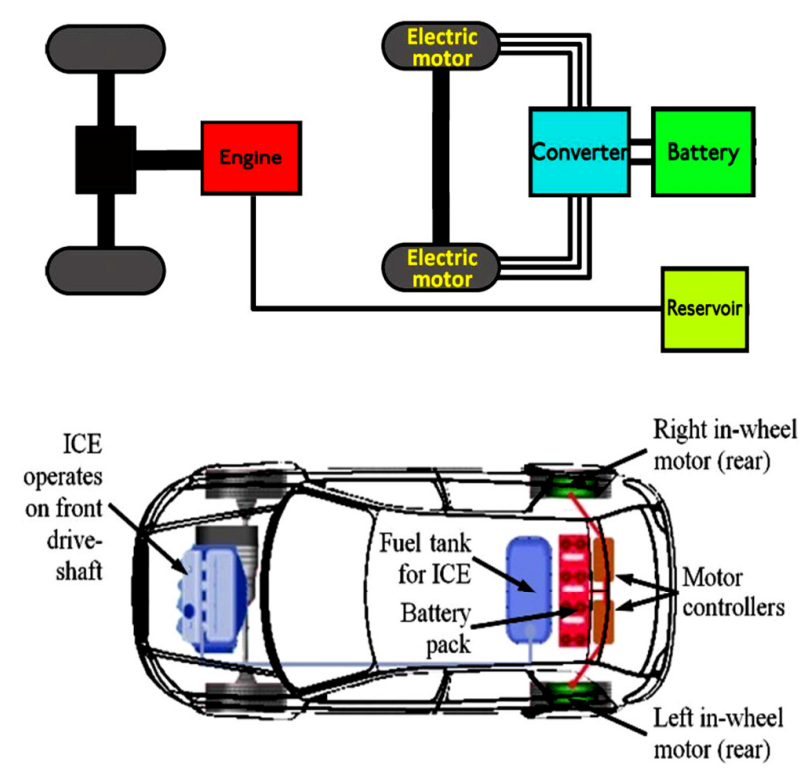

Figure 1. A split-parallel through-the-road hybrid electric vehicle.

asaifulazrin_mz@petronas.com.my 


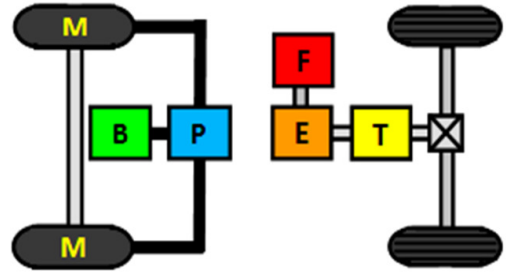

(a)

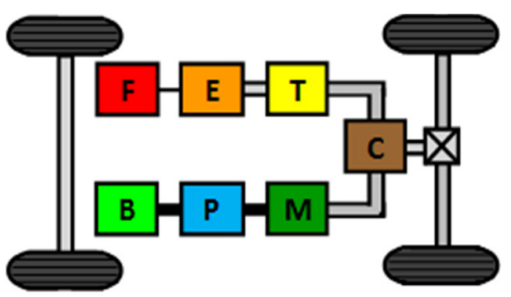

(b)

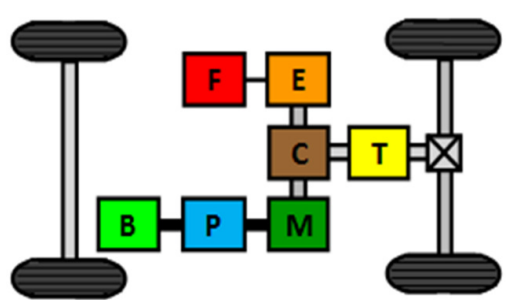

(c)

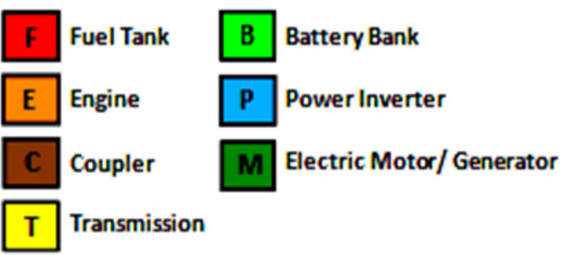

Figure 2. Parallel hybrid drive-train configurations: (a) TTRIWM split-axle parallel HEV; (b) single-axle, post-transmission parallel HEV; (c) single-axle, pre-transmission parallel HEV $[1,2]$

\section{Torque-Speed Relationship of Split- Axle Parallel Hybrid}

A parallel hybrid vehicle is essentially a torque-coupled system consisting of a mechanically-coupled drive-train. An ordinary parallel hybrid has some form of coupling device such as a pulley, gear or chain assembly, which adds together mechanical powers from the two sources. Figure 3 shows a parallel hybrid drive-train represented by a 3-port, 2-degree-of-freedom mechanical system. Port 1 is a unidirectional input (connected to the ICE), while port 2 (connected to the motor) and port 3 (connected to the wheels) are bidirectional input or output of the system (at least one must be an output at any time) $[3,4]$.

Ports 1 and 2 can either be connected directly to the power sources or through a mechanical transmission. Ignoring losses, power input to the torque coupler is equal to its power output, as expressed below, Eq. (1), where $\tau$ and $\omega$ represent torque and speed respectively of the coupling device and individual sources:

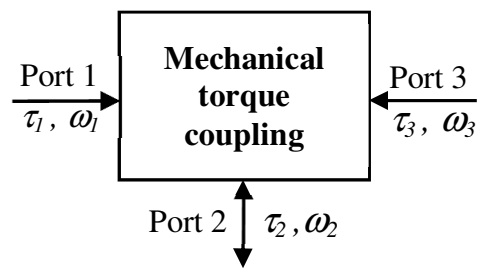

Figure 3. Three-port representation of a torque-coupled parallel hybrid drive-train.

$$
\tau_{3} \omega_{3}=\tau_{1} \omega_{1}+\tau_{2} \omega_{2}
$$

Torque output of the mechanical coupler $\tau_{3}$ can be expressed as:

$$
\tau_{3}=k_{1} \tau_{1}+k_{2} \tau_{2}
$$

where $k_{1}$ and $k_{2}$ are structural parameters of the coupling system, described for example by gear ratios, and are thus fixed parameters of the system. The contributing torques $\tau_{1}$ and $\tau_{2}$ are independent of each other and thus, can be individually controlled. However, due to power conservation, Eq. (1) leads to the constraint that speed of the power sources are linked together and governed by the relationship:

$$
\text { (c) } \omega_{3}=\frac{\omega_{1}}{k_{1}}=\frac{\omega_{2}}{k_{2}}
$$

Thus, the sources' speeds cannot be individually controlled. Coupling of the sources can consist of either single-shaft or double-shaft configuration. The former has the motor and engine connected in-line on the same shaft, while the latter has two separate shafts connected via the gear or chain assembly.

The split-axle, TTR parallel hybrid is a torquecoupled configuration - torque from the ICE and electric motor are added up through the vehicle chassis, wheels and road, without a coupling device. It is topologically similar to the dual-shaft parallel configuration, since the motor and ICE operate on separate drive axles. The torques can be individually controlled but their speeds are governed by Eq. (3).

In the case of a retrofit-conversion TTR-IWM vehicle, the ICE is connected to a multi-gear transmission (existing) while there is no transmission for the motor since it is in the wheel hub (similar to a directly-coupled on-board motor). Hence, with port 3 connected to the front wheels and port 1 connected to the ICE, $k_{1}$ is determined by the gear position of the ICE's transmission. Port 2 is connected to the motor with $k_{2}=1$ (direct-coupled, in-wheel motor). Thus, Eq. (2) and Eq. (3) become:

$$
\begin{aligned}
& \tau_{3}=k_{1} \tau_{1}+\tau_{2} \\
& \omega_{3}=\frac{\omega_{1}}{k_{1}}=\omega_{2}
\end{aligned}
$$


The in-wheel motor speed $\omega_{2}$ is thus equal to the speed of the ICE-driven front wheels, $\omega_{3}$. This is similar to a double-shaft, device-coupled parallel drive-train with the motor shaft coupled directly to the front-wheel axle (post-transmission coupling) with $k=1$. Figure 4 and Figure 5 show simulated torque profiles of pretransmission and post-transmission hybrid drive-trains (see discussion below). Torque profiles of a TTR-IWM hybrid are similar to a single-axle post-transmission parallel hybrid.

\section{Comparisons of Torque Profile and Acceleration Performance}

To investigate difference in torque and acceleration between TTR-IWM (or split-parallel) hybrid and pretransmission hybrid vehicle, simulation tests of acceleration are carried out using ADVISOR, a software based on Matlab-Simulink and commonly used for advanced vehicular powertrain studies. A constant vehicle speed request of $300 \mathrm{~km} / \mathrm{h}$ is given as simulation input, resulting in each drivetrain attempting to provide maximum possible torque. The simulation tests are carried out on a small vehicle, mounted with electric motors of three different sizes (16-kW, 32-kW and 75-kW continuous power). Vehicle and motor specifications are given in Table 1 and Table 2 respectively.

Table 1. Simulation test vehicle specifications.

\begin{tabular}{|c|c|}
\cline { 2 - 2 } \multicolumn{1}{c|}{} & Small Car \\
\hline Base mass: & $500 \mathrm{~kg}$ \\
\hline IC Engine: & $1.0 \mathrm{~L} \mathrm{SI}$ \\
\hline ICE Max Power: & $41 \mathrm{~kW}$ \\
\hline Transmission: & $\begin{array}{c}4-\text { Speed } \\
\text { Automatic }\end{array}$ \\
\hline Wheel Radius: & $0.225 \mathrm{~m}$ \\
\hline Accessory Load: & Constant 700 W \\
\hline Powertrain Control: & $\begin{array}{c}\text { Conventional } \\
(4-S p d ~ A T)\end{array}$ \\
\hline
\end{tabular}

Table 2. Simulation test motor specifications.

\begin{tabular}{|c|c|c|c|}
\cline { 2 - 4 } \multicolumn{1}{c|}{} & PM16 & PM32 & AC75 \\
\hline $\begin{array}{c}\text { Motor } \\
\text { Type: }\end{array}$ & $\begin{array}{c}\text { Permanent } \\
\text { Magnet }\end{array}$ & $\begin{array}{c}\text { Permanent } \\
\text { Magnet }\end{array}$ & $\begin{array}{c}\text { AC } \\
\text { Induction }\end{array}$ \\
\hline $\begin{array}{c}\text { Cont. } \\
\text { Power: }\end{array}$ & $15.8 \mathrm{~kW}$ & $32 \mathrm{~kW}$ & $75 \mathrm{~kW}$ \\
\hline $\begin{array}{c}\text { Max. } \\
\text { Torque: }\end{array}$ & $124 \mathrm{Nm}$ & $150 \mathrm{Nm}$ & $271 \mathrm{Nm}$ \\
\hline $\begin{array}{c}\text { Peak } \\
\text { Efficiency: }\end{array}$ & $92 \%$ & $94 \%$ & $92 \%$ \\
\hline $\begin{array}{c}\text { Manufac- } \\
\text { turer: }\end{array}$ & $\begin{array}{c}\text { Unique } \\
\text { Mobility }\end{array}$ & $\begin{array}{c}\text { Unique } \\
\text { Mobility }\end{array}$ & $\begin{array}{c}\text { Westing- } \\
\text { house }\end{array}$ \\
\hline Weight: & $20.6 \mathrm{~kg}$ & $60.8 \mathrm{~kg}$ & $91 \mathrm{~kg}$ \\
\hline
\end{tabular}

\subsection{Torque Comparison}

Figures 4 and 5 show that motor torque profile in splitparallel hybrid is continuous (except for drops during gear change); but the torque profile in pre-transmission hybrid shows torque increase after every gear change (most obvious in the PM16 and PM32 motors). The reason for this difference is the effect and location of the ICE's transmission gearbox: in the pre-transmission hybrid, with every upshift of the gear, there is torque increase from any source connected to its input, including the electric motor's torque $[5,6]$.

In the split-parallel and post-transmission hybrid however, since the motor's torque is added after the gearbox, the torque is not multiplied by the gearbox, resulting in the smooth torque profiles. From Figures 4 and 5, it can also be seen that in both drivetrains, the PM16 (16-kW permanent-magnet) motor has the highest torque profiles, followed by PM32 and AC75 motors. Power delivered by the motor is the product of torque and speed. As can be seen from Figures 6 and 7, which show operation maps of the PM16 and PM32 motors, the operating points do not fall in the same speed region.

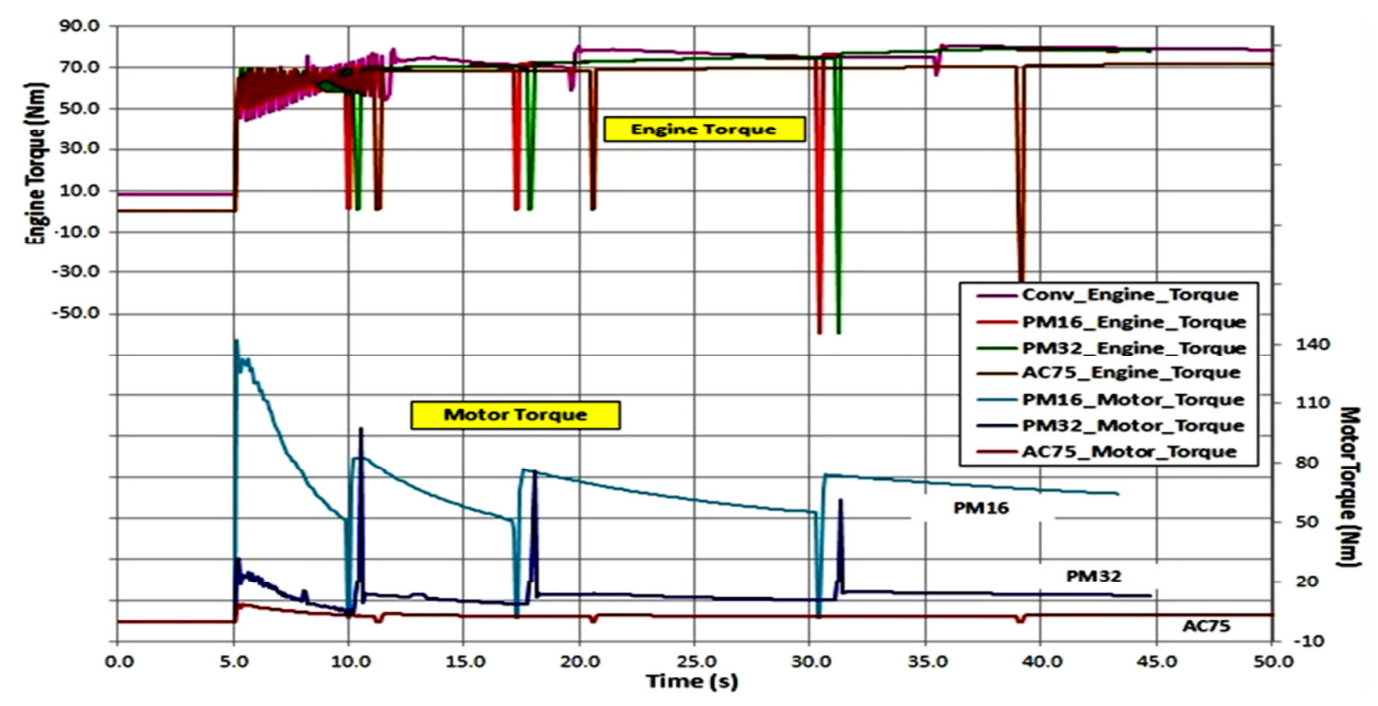

Figure 4. Engine and motor torque profiles in pre-transmission hybrid drive-train. 


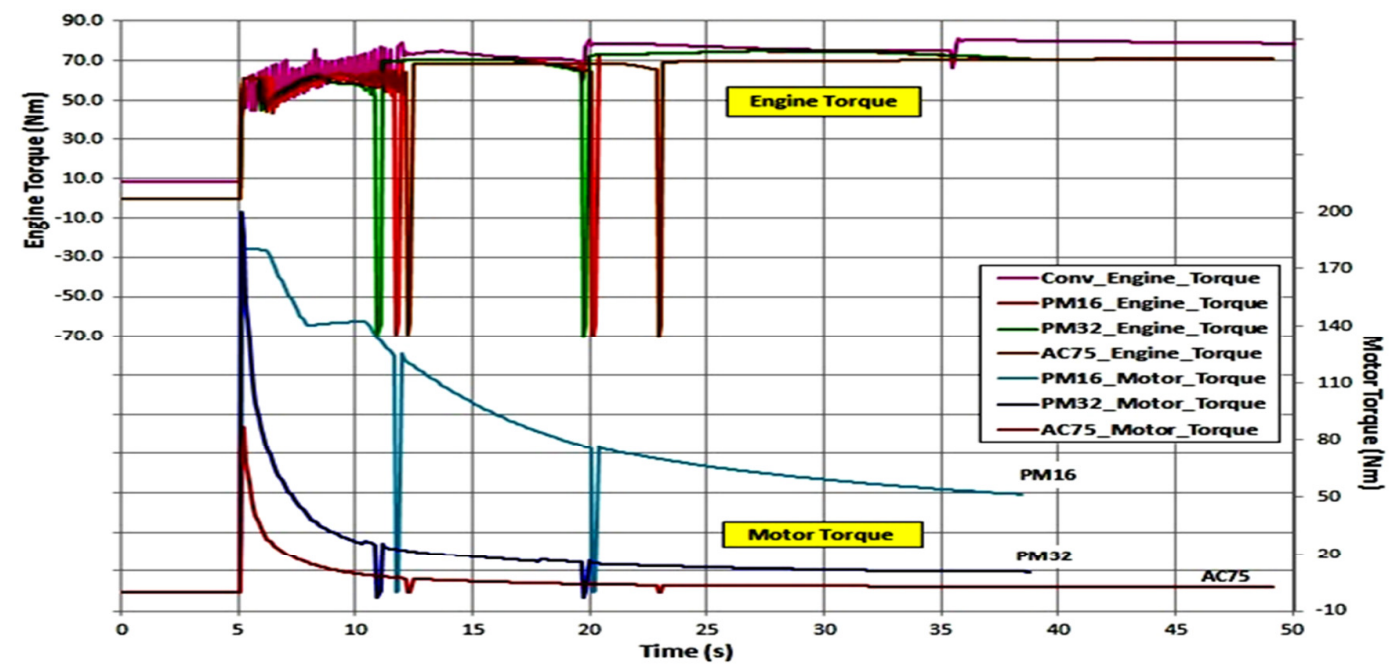

Figure 5. Engine and motor torque profiles in post-transmission hybrid drive-train.

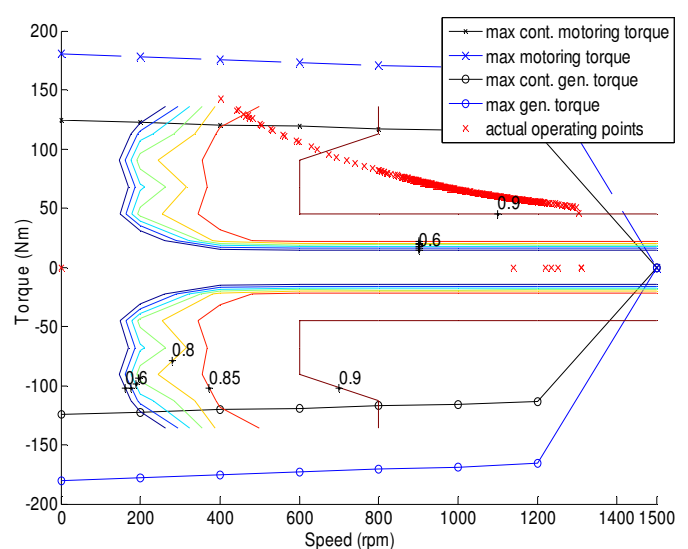

(a)

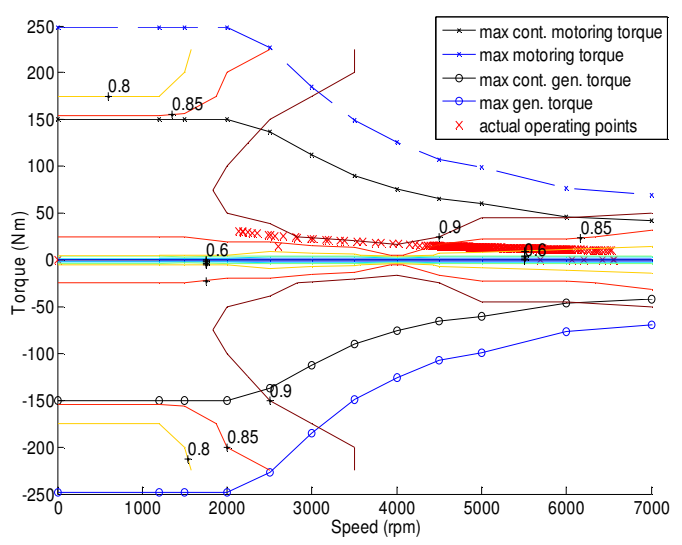

(b)

Figure 6. Operation map of (a) PM16 motor and (b) PM32 motor in pre-transmission hybrid configuration.

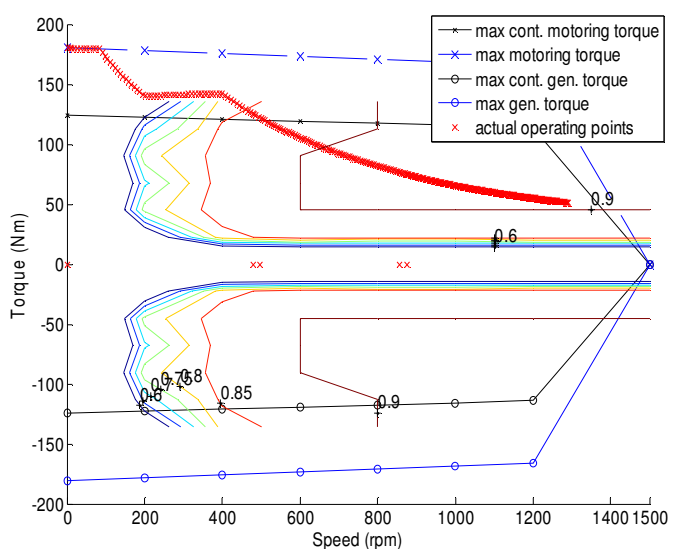

(a)

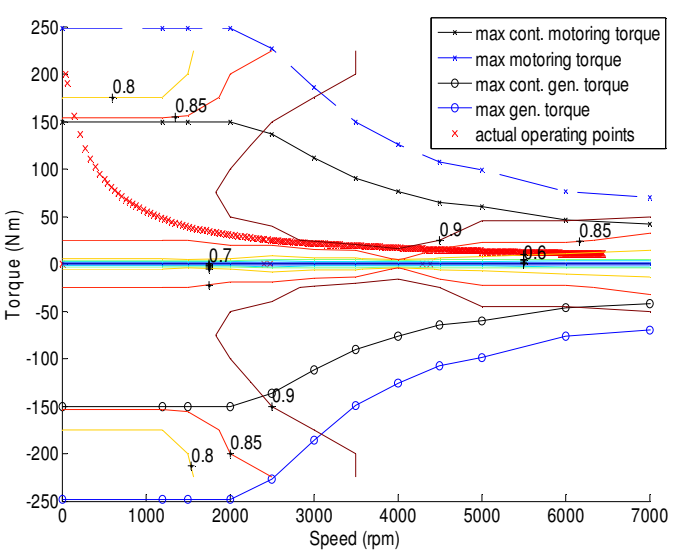

(b)

Figure 7. Operation map of (a) PM16 motor and (b) PM32 motor in post-transmission hybrid configuration. 
Figure 8(a) shows time chart of motor speed for both PM 16 and PM 32 motors, in a post-transmission hybrid. If both motor torque curves are plotted on the same graph of torque vs. speed as in Figure 8(b), the torque difference is not as staggering as it seems in the charts of torque vs. time in Figure 5. The different speed regions between PM16 and PM 32 motors can also be clearly seen in Figure 8(b).

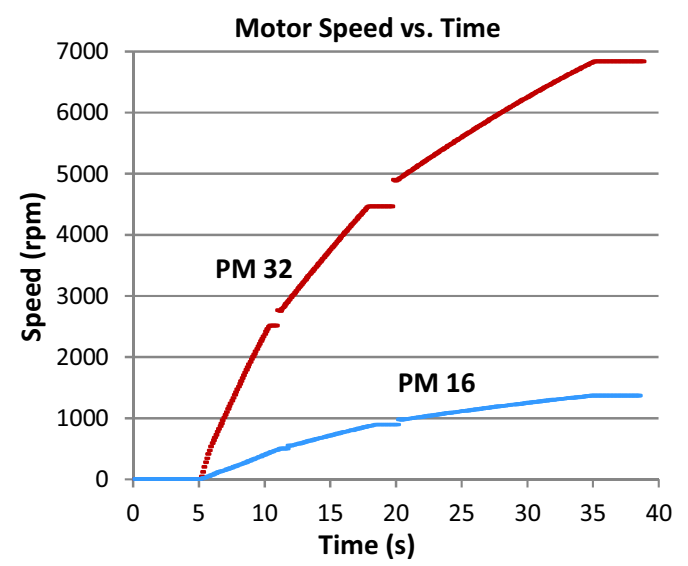

(a)
Figures 9, 10 and 11 show that motor torque profiles in the split-parallel hybrids are higher than those in the pre-transmission hybrids, for all motors: PM16, PM32 and AC75. This is related to the motors' operating speeds.

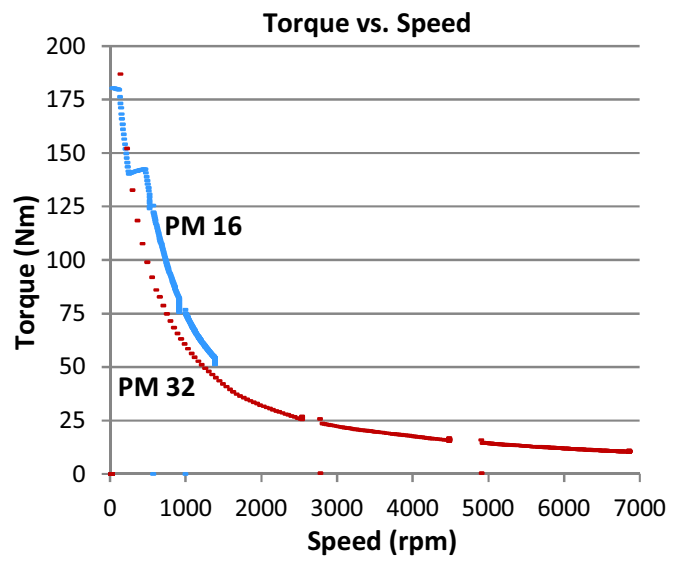

(b)

Figure 8. (a) Motor speed vs. time and (b) torque vs. speed for PM16 and PM32 motors in post-transmission hybrid configuration.

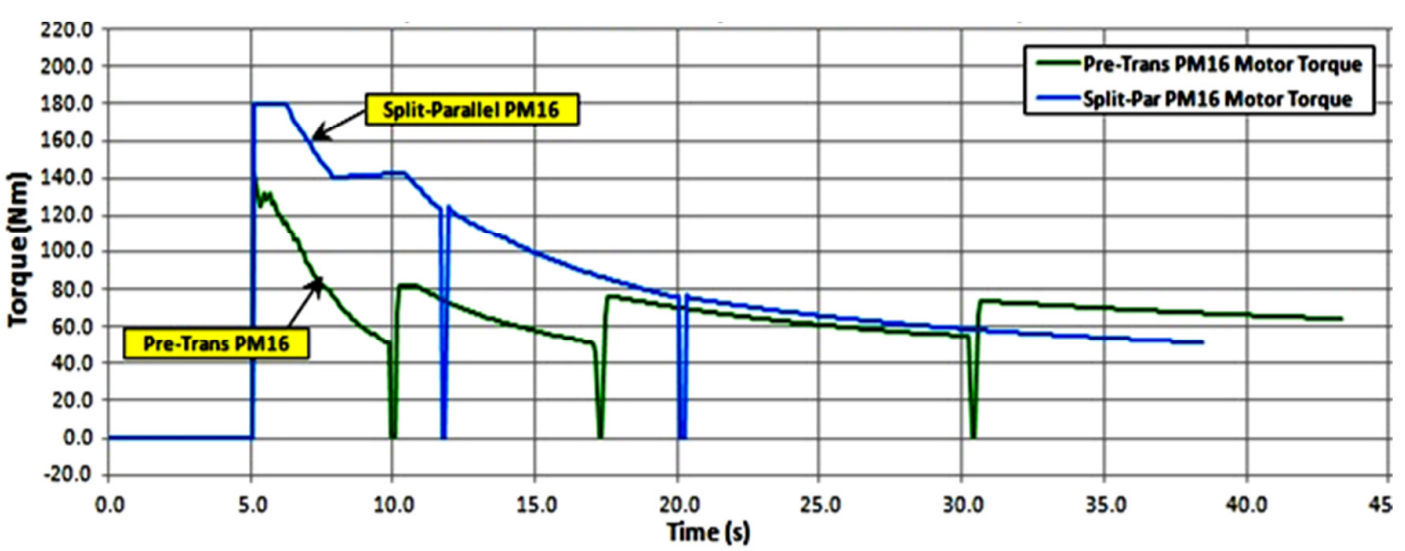

Figure 9. Motor torque profile of pre-transmission \& split-parallel hybrids: 16-kW motor.

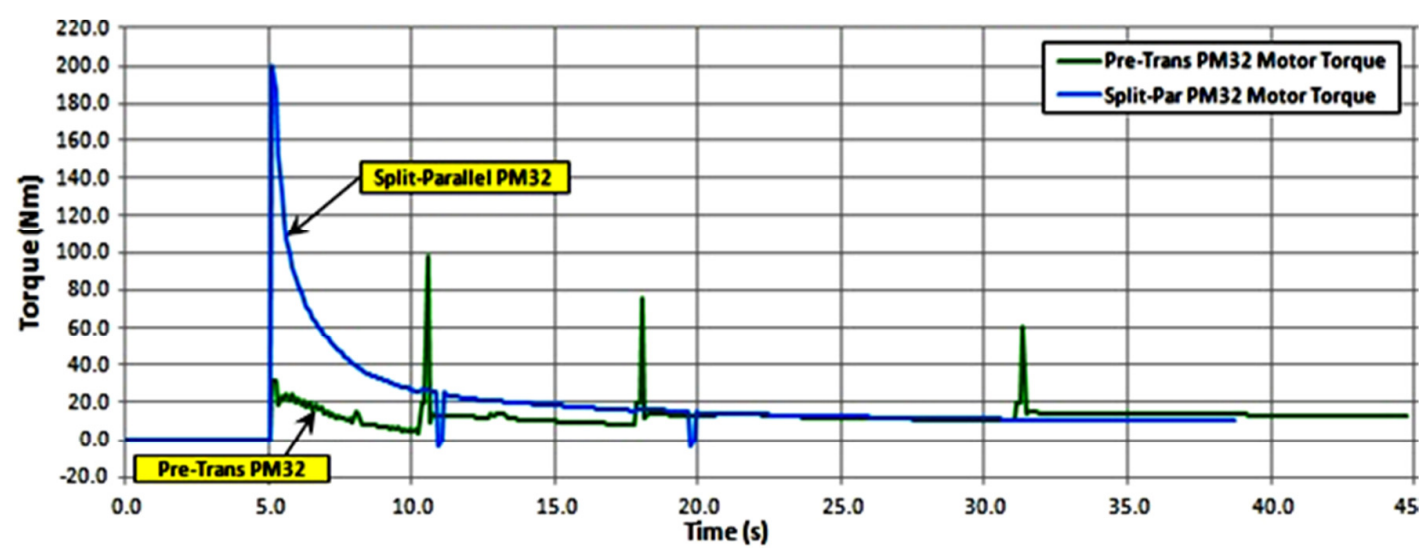

Figure 10. Motor torque profile of pre-transmission \& split-parallel hybrids: $32-\mathrm{kW}$ motor. 


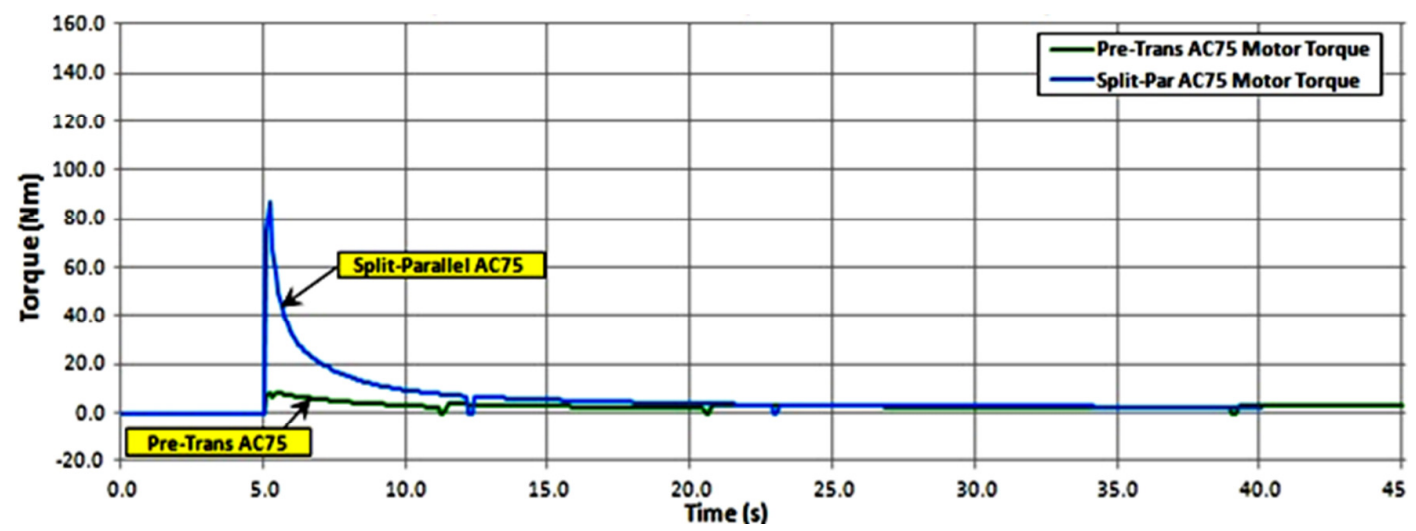

Figure 11. Motor torque profile of pre-transmission \& split-parallel hybrids: 75-kW motor.

As shown in Figure 12 and Figure 13, the pretransmission motors operate almost instantaneously to a certain speed - about $350 \mathrm{rpm}$ for PM16 and $1800 \mathrm{rpm}$ for PM32 - while the post-transmission motors operate from zero speed.

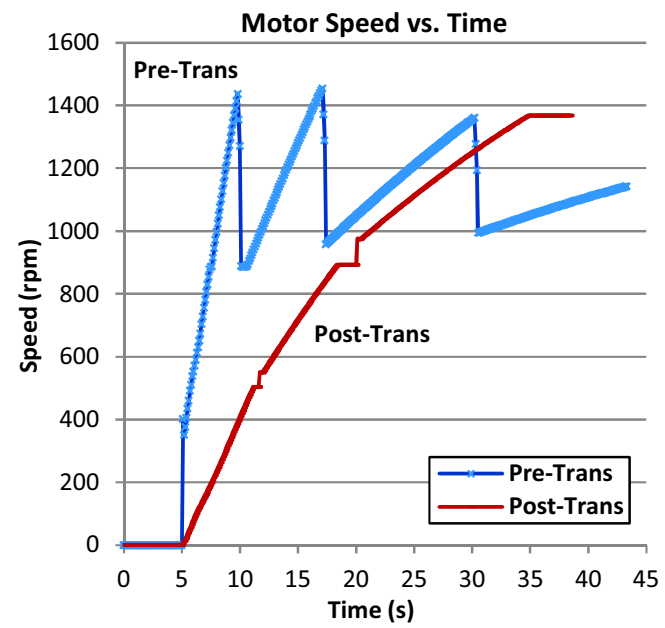

(a)

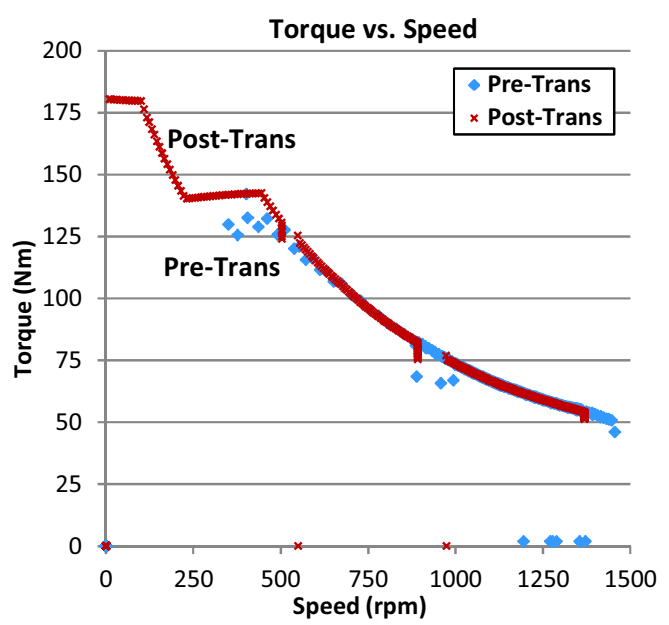

(b)

Figure 12. Comparison of pre-transmission and posttransmission hybrid configurations with PM16 motor: (a) motor speed vs. time and (b) torque vs. speed.
In the first 18 seconds, the post-transmission motor produces higher torque at low speeds, while the pretransmission motor delivers lower torque due to its lower initial speeds. After about 18 seconds, each motor then operates in the same torque and speed region.

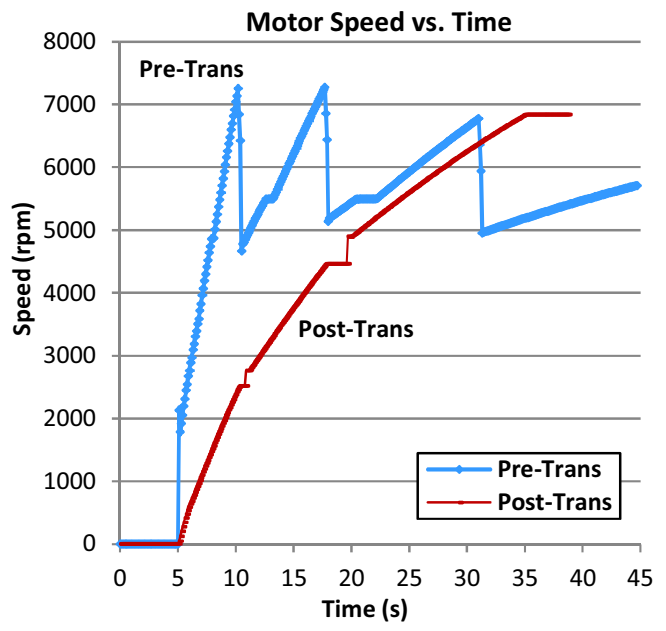

(a)

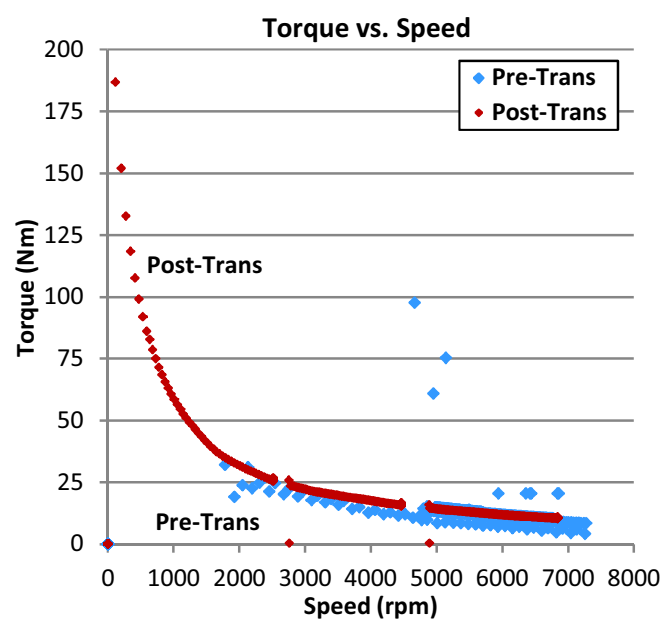

(b)

Figure 13. Comparison of pre-transmission and posttransmission hybrid configurations with PM32 motor: (a) motor speed vs. time and (b) torque vs. speed. 


\subsection{Acceleration Performance}

Figure 14 shows that with each motor, acceleration performance improves from the conventional vehicle, and is always better (faster) than the pre-transmission hybrid, with the AC75 hybrid showing the biggest difference and the PM16 hybrid having the fastest response. The same patterns are observed in fuel consumption (Fig. 15).

However, for emissions (Fig. 16), all TTR-IWM hybrids show increased levels from the pre-transmission hybrids, for all emission types (biggest difference in AC75 hybrid).
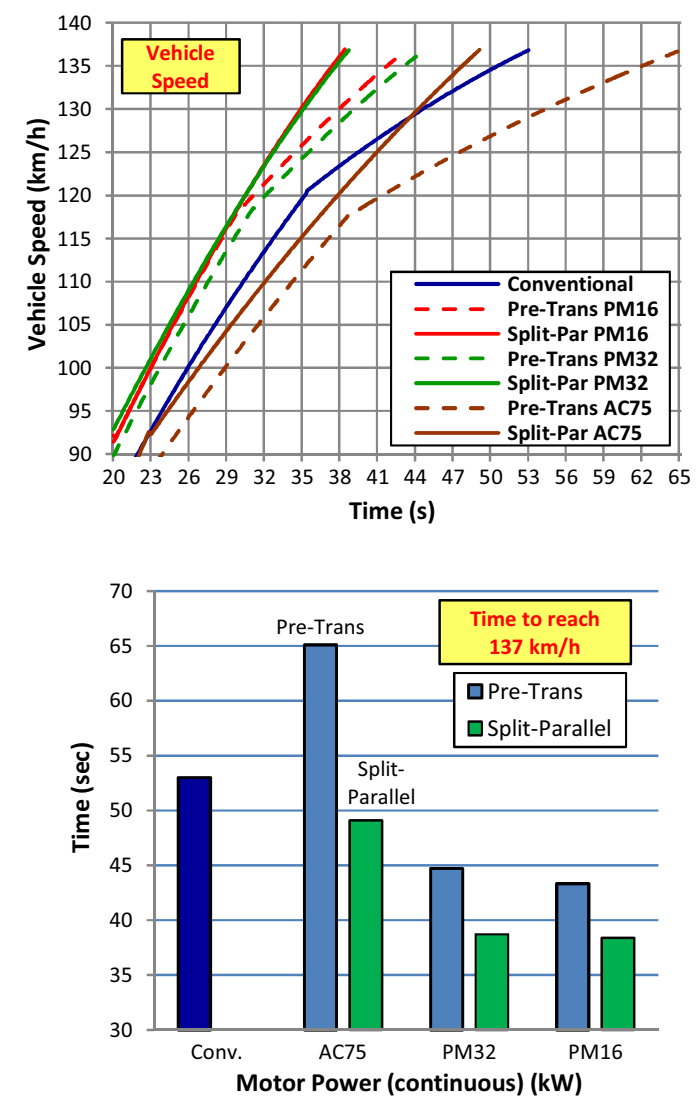

Figure 14. Vehicle speed and acceleration performance comparison.

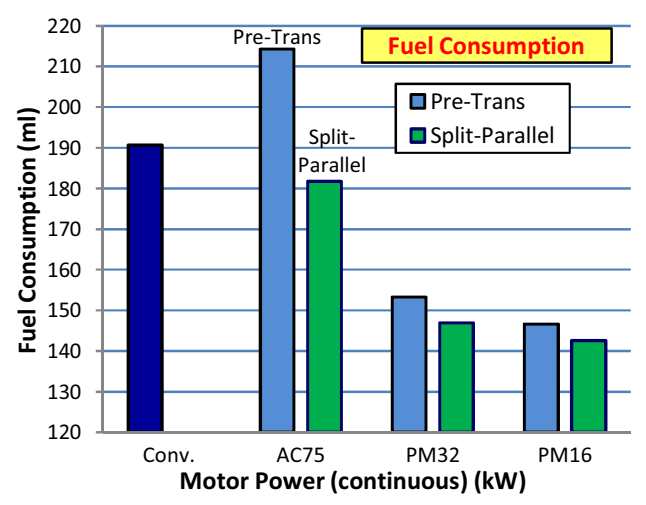

Figure 15. Fuel consumption comparison.
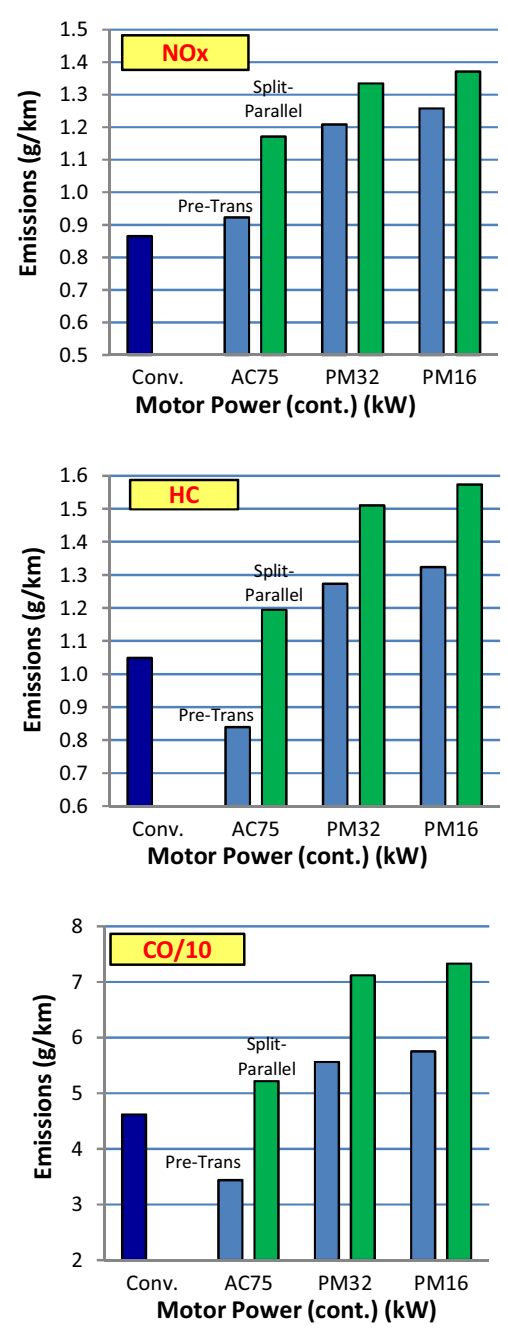

Figure 16. Emissions comparison - NOx, $\mathrm{HC}$ and $\mathrm{CO}$.

Figures 17 and 18 show power flow and energy usage of each sub-system within the hybrid powertrain, for both pre-transmission and post-transmission hybrids. From Table 3, it is seen that total energy delivered by the motor in a pre-transmission hybrid vehicle is higher than that in a split-parallel hybrid, for all motor sizes. Similarly, total engine output is always higher in the pre-transmission hybrid, for any motor, resulting in overall more fuel consumption in the pre-transmission hybrid, compared to the split-parallel.

This is due to the higher motor torque and power in the post-transmission hybrid, which results in the vehicle reaching the final desired speed faster than the pretransmission hybrid. Thus, the split-parallel hybrid has better fuel economy across all motor sizes, with the highest fuel savings of $25.2 \%$ in the PM16 TTR hybrid. 


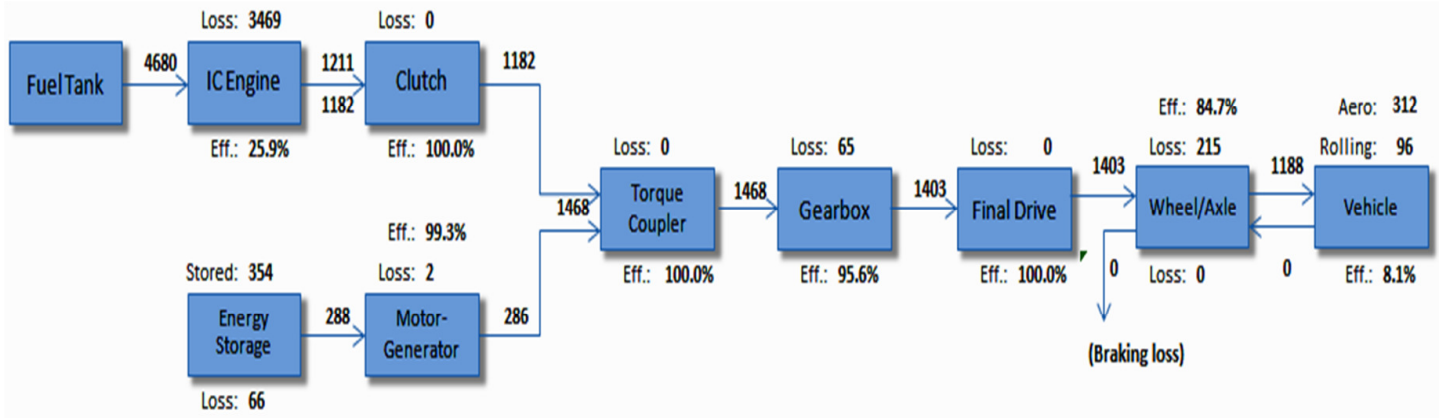

Figure 17. Power flow and energy usage in pre-transmission hybrid drive-train

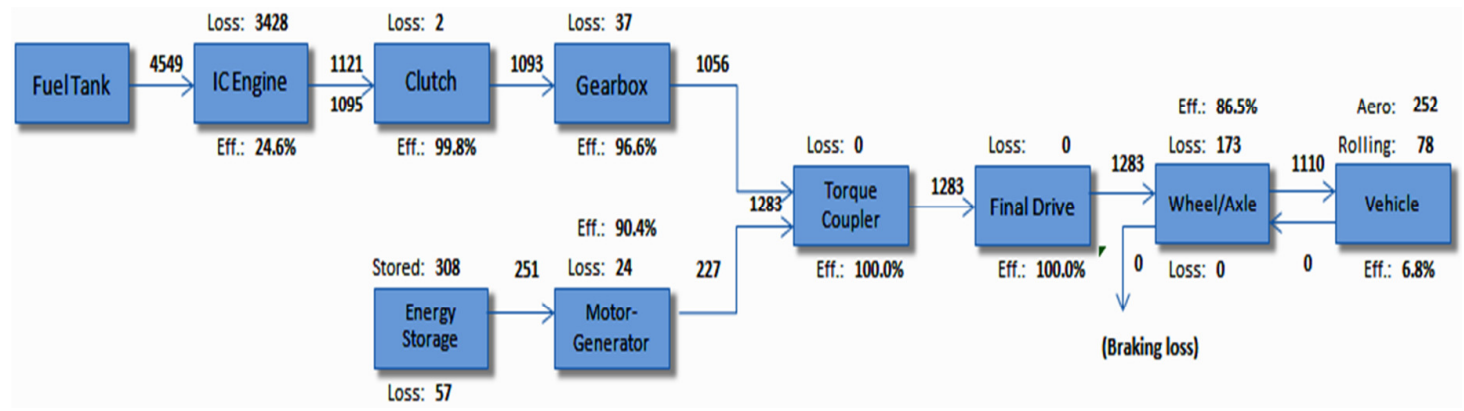

Figure 18. Power flow and energy usage in post-transmission hybrid drive-train

Figure 19 shows graphs of fuel consumption versus the combustion engine's output energy, showing straightline relationship as expected, for both drivetrains. However, it can be seen that the graph of pre-transmission hybrid lies below the graph of post-transmission (splitaxle) hybrid, which means that for every operating point of the ICE, the post-transmission hybrid consumes slightly more fuel, or is less efficient, than the pretransmission hybrid.

This is corroborated by the ICE average efficiency values in Table 3, which shows post-transmission hybrids having slightly lower ICE efficiencies. Although engine efficiency of the post-transmission hybrid is slightly lower (less than 2.2 percentage points), overall it still consumes less fuel to reach the final target speed in the acceleration simulation, compared to the pre-transmission hybrid, for all motor sizes.

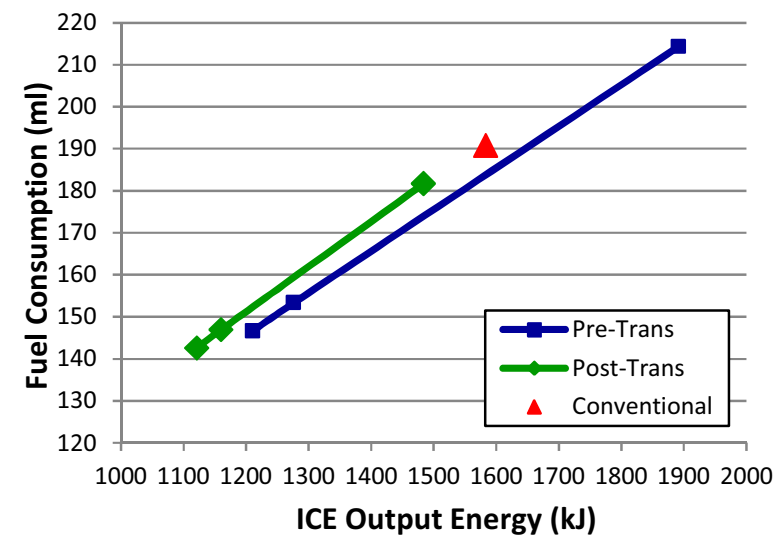

Figure 19. Fuel consumption vs. ICE output energy.

\section{Conclusions}

A split-axle parallel hybrid configuration enables conventional vehicles to be converted into a hybrid electric vehicle with minimal physical modification, to be a through-the-road, post-transmission hybrid vehicle with in-wheel motors (TTR-IWM). This paper describes torque-speed relationship for the TTR-IWM hybrid, comparing it to the pre-transmission, parallel hybrid with on-board motor. Simulation results of acceleration test are provided, comparing torque profiles and acceleration performance of the pre-transmission and posttransmission drivetrains, for three different electric motor sizes.

Results show different operating regions of the pretrans and post-trans motors, leading to different speed and torque profiles. It is found that, although ICE average efficiency in the post-transmission hybrid is slightly lower than in the pre-transmission hybrid, the post-transmission hybrid vehicle has better overall fuel economy and acceleration performance than the pre-transmission hybrid vehicle.

\section{Acknowledgment}

This work is partly funded by an ERGS grant (Exploratory Research Grant Scheme) from the Ministry of Higher Education (MOHE), Malaysia.

\footnotetext{
asaifulazrin_mz@petronas.com.my
} 
Table 3. Performance comparison of split-parallel and pre-transmission parallel hybrid vehicles.

\begin{tabular}{|c|c|c|c|c|c|c|c|}
\cline { 2 - 8 } \multicolumn{1}{c|}{} & $\begin{array}{c}\text { ICE } \\
\text { Output } \\
(\mathbf{k J})\end{array}$ & $\begin{array}{c}\text { Motor } \\
\text { Output } \\
(\mathbf{k J})\end{array}$ & $\begin{array}{c}\text { Motor } \\
\text { Ave. Eff. } \\
(\boldsymbol{\%})\end{array}$ & $\begin{array}{c}\text { ICE } \\
\text { Ave. } \\
\text { Eff. } \\
(\boldsymbol{\%})\end{array}$ & $\begin{array}{c}\text { Overall } \\
\text { Eff. } \\
(\boldsymbol{\%})\end{array}$ & $\begin{array}{c}\text { Fuel } \\
\text { Cons. } \\
(\mathbf{m l})\end{array}$ & $\begin{array}{c}\text { Fuel } \\
\text { Savings } \\
(\%)\end{array}$ \\
\hline Conventional & 1583 & $\mathrm{n} / \mathrm{a}$ & $\mathrm{n} / \mathrm{a}$ & 26.6 & 8.7 & 190.7 & N/A \\
\hline Split-Par AC75 & 1484 & 100 & 89.3 & 26.1 & 8.0 & 181.7 & 4.7 \\
\hline Split-Par PM32 & 1160 & 239 & 94.0 & 25.2 & 7.0 & 146.9 & 23.0 \\
\hline Split-Par PM16 & 1121 & 227 & 90.4 & 25.2 & 6.8 & 142.6 & 25.2 \\
\hline Pre-Trans AC75 & 1891 & 135 & 89.1 & 28.3 & 10.3 & 214.3 & -12.4 \\
\hline Pre-Trans PM32 & 1276 & 296 & 99.4 & 26.7 & 8.1 & 153.3 & 19.6 \\
\hline Pre-Trans PM16 & 1211 & 288 & 99.5 & 26.5 & 8.1 & 146.7 & 23.1 \\
\hline
\end{tabular}

\section{References}

1. S.A. Zulkifli, S. Mohd, N. Saad, A.R.A. Aziz, Appl. Mech. and Materials AMM 663, 498-503 (2014)

2. S.A. Zulkifli, S. Mohd, N. Saad, A.R.A. Aziz, Int. Journal of Auto. and Mech. Eng. IJAME 11, 2793-2808 (2015)

3. M. Ehsani, Y. Gao, A. Emadi, Modern electric, hybrid electric, and fuel cell vehicles: fundamentals, theory and design, 2nd ed., CRC Press (2010)

4. C.C. Chan, A. Bouscayrol, K. Chen, IEEE Trans. Vehicular Technology 59, 589-98 (2010)

5. Z. Rahman, M. Ehsani, K.L. Butler, Future Engines SP-1559, 2000-01-3062 (2000)
6. Z. Rahman, K.L. Butler, M. Ehsani, SAE 2000 World Congress, 2000-01-0994 (2000)

7. B. Asaei, M. Habibidoost, IEEE Vehicle Power and Propulsion Conference, 1-5 (2010)

8. M. Young, G.M. Molen, D. Oglesby, K. Crawford, K. Walp, R. Lewis, C. Whitt, S. Phillips, IEEE Vehicle Power and Propulsion Conference, 511-518 (2007)

9. N. Fallahi, A.H. Niasar, Intelligent Systems in Electrical Engineering 4, 51-61 (2014)

asaifulazrin_mz@petronas.com.my 